\title{
Catalytic Hydroboration and Reductive Amination of Carbonyl Compounds by HBpin using a Zinc Promoter
}

\author{
Ravi Kumar, ${ }^{[a] \dagger}$ Parveen Rawal, ${ }^{[b] \dagger}$ Indrani Banerjee, ${ }^{[a]}$ Hari Pada Nayek, ${ }^{[c]}$ Puneet Gupta, ${ }^{* b]}$ and Tarun \\ K. Panda*[a]
}

\begin{abstract}
:
In this paper, the chemoselective hydroboration of aldehydes and ketones, catalyzed by $\mathrm{Zinc}(\mathrm{II})$ complexes $\left[\kappa^{2}-(\mathrm{PyCH}=\mathrm{NR}) \mathrm{ZnX}_{2}\right][\mathrm{R}=$ $\mathrm{CPh}_{3}, \mathrm{X}=\mathrm{Cl}$ (1) and $\mathrm{R}=$ Dipp (2,6-diisoropylphenyl) and $\mathrm{X}=\mathrm{I}(\mathbf{2})$ ], in the presence of pinacolborane (HBpin) in ambient temperature and solvent-free conditions, which produced corresponding boronate esters in high yield, is reported. Zinc metal complexes $\mathbf{1}$ and $\mathbf{2}$ were derived in $80-90 \%$ yield from the reaction of iminopyridine $[\mathrm{PyCH}=\mathrm{NR}]$ with anhydrous zinc dichloride in dichloromethane at room temperature. The solid-state structures of both zinc complexes were confirmed using X-ray crystallography. Zinc complex 1 was also used as a competent pre-catalyst in the reductive amination of carbonyl compounds with HBpin under mild and solvent-free conditions to afford a high yield (up to $97 \%$ ) of the corresponding secondary amines. The wider substrate scope of both reactions was explored. Catalytic protocols using zinc as a pre-catalyst demonstrated an atomeconomic and green method with diverse substrates bearing excellent functional group tolerance. Computational studies established a plausible mechanism for catalytic hydroboration.
\end{abstract}

\section{Introduction}

Catalysis is regarded as a predominant tool among modern synthetic chemists. Globally, several research groups have used various catalytic methodologies. In particular, catalytic hydroelementation of unsaturated substrates employing a variety of metal complexes has received significant attention. Over the decades, H-element insertion into multiple bonds of the substrates, and achieving a series of functionalized products, represented atom-economical strategies. ${ }^{1}$ More recently however a variety of main group metals, ${ }^{2}$ transition metals, ${ }^{3}$ lanthanides,${ }^{4}$ and actindes ${ }^{5}$ have been recognized as valuable catalysts in hydroelementation reactions. Concurrently, versatile zinc metal complexes have also been investigated for their catalytic efficacy by several research groups. Zinc is known for its enormous importance in biological processes as a component in enzymes. ${ }^{6}$ Since zinc salts and complexes are abundant, inexpensive, and nontoxic, they are often used in a wide range of useful reactions. ${ }^{7}$ The closed-shell $\mathrm{d}^{10}$ configuration of zinc metal complexes, resembling the electronic and catalytic properties of early transition metals, makes the zinc metal complexes as unique catalysts in Negishi coupling and Reformatsky reactions wellknown from textbooks. ${ }^{8-9}$

In the last few years, researchers have witnessed tremendous advancement in hydroelementation reactions namely hydrosilylation, hydroamination reactions on $\mathrm{C}-\mathrm{C}, \mathrm{C}-\mathrm{N}$, and $\mathrm{C}-\mathrm{O}$ multiple bonds promoted by various $\mathrm{Zn}$ (II) catalysts. ${ }^{10-15}$ Most recently, catalytic hydroboration strategies have generated intense interest amongst researchers worldwide. Organoboron compounds acquired from chemical conversions act as valuable constituent substrates in various organic reactions. ${ }^{16} \mathrm{Zn}(\mathrm{OTf})_{2^{-}}$ mediated hydroboration of internal and terminal alkynes, which demonstrated broad substrate scope, chemoselectivity, and high functional-group tolerance, has been reported. ${ }^{17}$ Recently, a Znalkyl metal complex, supported by an $\mathrm{N}$-donor ligand, which proved to be an effective catalyst for the reduction of $\mathrm{N}$ heteroarenes, was developed. ${ }^{18}$ Under ambient conditions, 10 mol\% of the complex provided $80-97 \%$ of the 1,2-addition products. Nembanna and Nikonov research group exhibited the synthesis of conjugated bis-guadinate and $\mathrm{NacNac}$ ligand supported $\mathrm{Zn}-\mathrm{H}$ complexes respectively and examined their catalytic activities toward hydroboration and hydrosilylation of ketones, pyridines and phenanthroline. ${ }^{19-20}$ Very low catalyst loading effectively reduced the ketone substrates at room temperature under solvent-free conditions within six hours. Their research was extended and the same catalyst was shown to be highly proficient in the chemoselective hydroboration of aryl and alkyl isocyanates. ${ }^{21}$ Although the true metal catalysts received enormous recognition, some recent reports by the scientists reveal the formation of the organoboron compounds proceed via the hidden boron catalysts achieved from HBpin, HBcat or 9$\mathrm{BBN}^{22}$

Over the past few years, in keeping with recent trends in catalysis research, our research group has developed versatile $\mathrm{Zn}$ (II) metal complexes and examined a variety of $\mathrm{C}-\mathrm{X}(\mathrm{X}=\mathrm{N}, \mathrm{B}, \mathrm{Si})$ bond formations from unsaturated substrates. ${ }^{23}$ Continuing with this research, we present here the synthesis and characterization of two $\mathrm{Zn}$ (II) complexes supported by an iminopyridine ligand. The $\mathrm{Zn}$ (II) catalysts were investigated for their efficiency in the hydroboration of carbonyl compounds and imine derivatives. Under neat conditions at $60{ }^{\circ} \mathrm{C}$, the catalysts demonstrated competency toward the hydroboration reactions and excellent yields of boronate esters and $\mathrm{N}$-boryl amines were obtained. The zinc monohydride complex was observed to be the key intermediate when DFT studies were carried out to establish the mechanistic pathway. 
Reported Zn(II) catalysts<smiles>[H][Z10]1=C2C(C)=CC(C)=C(C)N(c3c(C)cccc3C1)N2c1c(C)cccc1C</smiles>

Nikonov et al. ${ }^{15}$

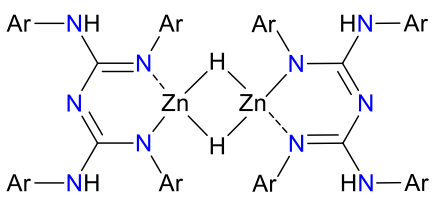

Nembanna et al. ${ }^{19}$<smiles>C=C1CN(CCCC)[Z17]2(CC)OC(=C/I)/C(=C\I)O[Z17]2(CC)Cc2cc(C(C)(C)C)cc(C(C)(C)C)c21</smiles>

Yuan et al. ${ }^{18}$

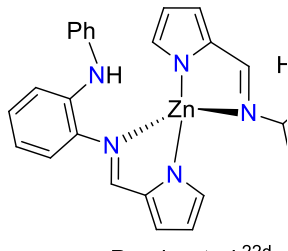

Panda et al. ${ }^{22 d}$

This work

$$
\begin{aligned}
& \mathrm{R}_{1}=\text { aryl, alkyl } \\
& \mathrm{R}_{2}=\mathrm{H} \text {, aryl, alkyl }
\end{aligned} \underset{\begin{array}{c}
\text { neat, r.t. } / 60^{\circ} \mathrm{C}, \\
12-15 \mathrm{~h}
\end{array}}{\stackrel{\text { cat. 1-2 }(5 \mathrm{~mol} \%)}{\longrightarrow}}
$$

$$
\begin{aligned}
& \begin{array}{c}
\text { cat. } 1(5 \mathrm{~mol} \%) \\
12-15 \mathrm{~h}
\end{array} \\
& \mathrm{R}=\mathrm{CPh}_{3} ; \mathrm{X}=\mathrm{Cl}(\mathbf{1})
\end{aligned}
$$

Figure 1. Selected $\mathrm{Zn}$ (II) metal complexes promoted $\mathrm{C}-\mathrm{X}(X=N, B, \mathrm{Si})$ bond formation from unsaturated substrates. This work describes $\mathrm{Zn}$ (II)-catalyzed hydroboration to ketones, aldehydes, and reductive amination of aldehydes and amines.

\section{Results and Discussion}

\section{Synthesis and Structure of Zinc Complexes (1-2).}

The iminopyridine ligands $[\mathrm{PyCH}=\mathrm{NR}]$ were synthesized in good yields by the reaction of pyridine-2-carboxaldehyde with tritylamine or 2,6-diisopropylaniline in the presence of methanol and a catalytic amount of glacial acetic acid at room temperature (Scheme 1), as mentioned in the reported literature. ${ }^{24}$ The zinc complexes $\left[\kappa^{2}-(\mathrm{PyCH}=\mathrm{NR}) \mathrm{ZnX}_{2}\right]\left[\mathrm{R}=\mathrm{CPh}_{3}, \mathrm{X}=\mathrm{Cl}(\mathbf{1})\right.$ and $\mathrm{R}=$ Dipp, $X=1$ (2)] were achieved from the reaction between iminopyridine $[\mathrm{PyCH}=\mathrm{NR}]$ and anhydrous zinc halide in a 1:1 molar ratio in dichloromethane solvent at room temperature in quantitative yields (Scheme 1). These zinc complexes (1-2) were characterized using standard spectroscopic and analytical techniques. The molecular structures of the complexes were confirmed by single-crystal $\mathrm{X}$-ray diffraction analysis.

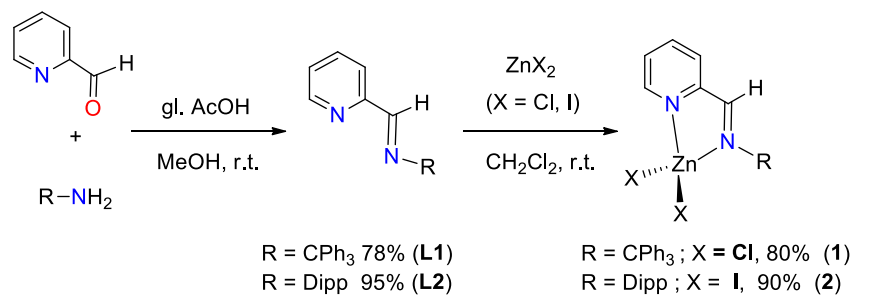

Scheme 1. Synthesis of the $\mathrm{Zn}(\mathrm{II})$ complexes from iminopyridine $[\mathrm{PyrCH}=\mathrm{NAr}]$ ligands.

The resonance signal of the imine proton in the ${ }^{1} \mathrm{H}$ NMR was observed at $\delta_{\mathrm{H}}=7.77 \mathrm{ppm}$ and $8.03 \mathrm{ppm}$ for complexes 1 and 2 respectively, which are in the same range as those of the ligand $[\mathrm{PyCH}=\mathrm{NR}]$. Single crystals of complexes suitable for X-ray analysis were grown from the toluene solution at $-35^{\circ} \mathrm{C}$. The solid-state structures of zinc complexes $\mathbf{1}$ and $\mathbf{2}$ displayed in Figures 2 and 3 respectively confirm the coordination of the iminopyridine ligand to the zinc center. The pertinent crystallographic data and refinement parameters are given in TS1 (in the supporting information).

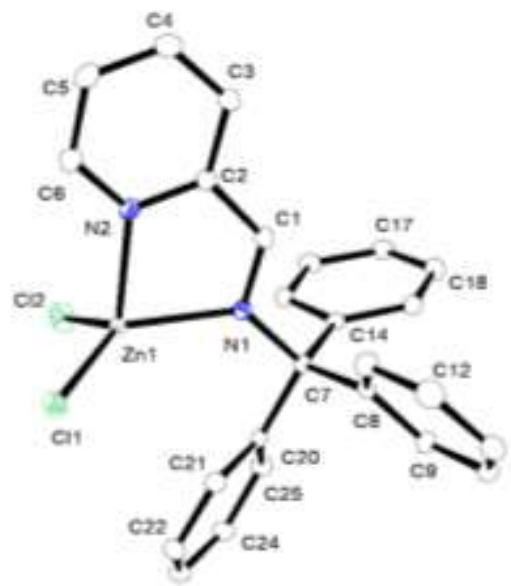

Figure 2. Solid-state structure of zinc complex 1. Selected bond lengths $(\AA)$ and bond angles $\left({ }^{\circ}\right)$ are given: $\mathrm{Zn}(1)-\mathrm{N}(1) 2.0979(16), \mathrm{Zn}(1)-\mathrm{N}(2) 2.0773(16)$, $\mathrm{Zn}(1)-\mathrm{Cl}(1)$ 2.2201(5), Zn(1)-Cl(2) 2.2053(5), N(1)-Zn(1)-N(2) 80.27(6), N(1)$\mathrm{Zn}(1)-\mathrm{Cl}(1)$ 125.25(5), N(2)-Zn(1)-Cl(2) 109.96(5), N(1)-Zn(1)-Cl(2) 110.19(5), $\mathrm{N}(2)-\mathrm{Zn}(1)-\mathrm{Cl}(1)$ 105.95(5), Cl(2)-Zn(1)-Cl(1) 117.45(2). CCDC No 2117961.

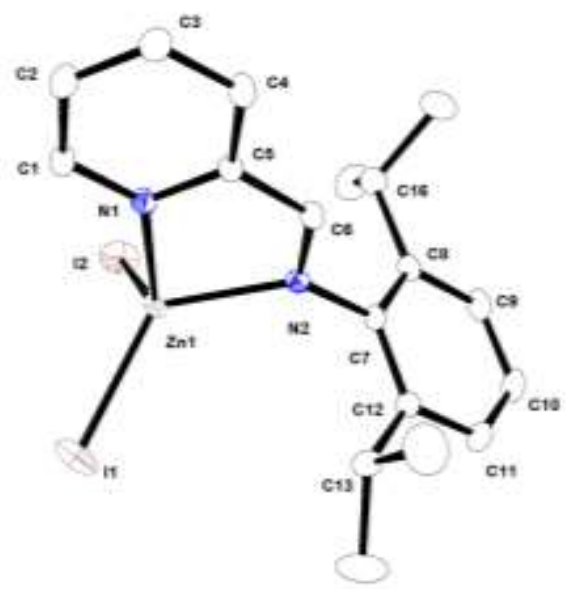

Figure 3. Solid-state structure of zinc complex 2. Selected bond lengths $(\AA)$ and bond angles $\left(^{\circ}\right)$ are given: $\mathrm{Zn}(1)-\mathrm{N}(1)$ 2.087(3), $\mathrm{Zn}(1)-\mathrm{N}(2) 2.120(3), \mathrm{Zn}(1)-\mathrm{I}(1)$ 2.5165(6), Zn(1)-I(2) 2.5083(6), N(1)-Zn(1)-N(2) 79.34(11), N(1)-Zn(1)-I(1) 110.76(9), N(2)-Zn(1)-I(2) 110.65(8), N(1)-Zn(1)-I(2) 116.41(9), N(2)-Zn(1)I(1) 120.98(8), I(2)-Zn(1)-I(1) 114.33(2). CCDC 2117962.

Metal complexes 1 and 2 crystallize in the monoclinic $P 2_{1} / c$ and $P 2_{1} / n$ space groups respectively. In both the metal complexes, a four-fold coordination around the central zinc ion is observed and the geometry around the zinc(II) ion is best described as a distorted tetrahedral due to the $\kappa^{2}$-coordination of the ligand $[\mathrm{PyCH}=\mathrm{NAr}]$ through the pyridine and imine nitrogen atoms. 
Additionally, two chloride ions are bonded to a zinc ion. A fivemembered metallacycle $\mathrm{Zn1}-\mathrm{N} 1-\mathrm{C} 1-\mathrm{C} 2-\mathrm{N} 2$ is formed in each case. The $\mathrm{Zn}-\mathrm{N}$ bond distances of 2.0979(16) and 2.0773(16) $\AA$ for complex 1 and 2.087(3) and 2.120(3) $\AA$ for complex 2 are similar and were diagnosed as coordination bonds. These bond distances are in a range similar to that of previously reported imino zinc complexes. ${ }^{23 \mathrm{~d}}$

\section{Hydroboration of ketones and aldehydes.}

To examine the efficiency of zinc compounds as pre-catalysts, initial screening of catalytic hydroboration of benzophenone with pinacolborane (HBpin) was carried out using $5 \mathrm{~mol} \%$ of precatalyst loading at room temperature (Scheme 2 ). The results are outlined in Table 1

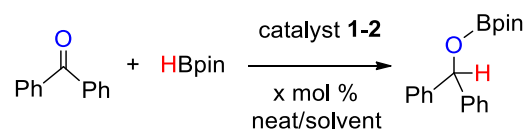

Scheme 2. Hydroboration of benzophenone catalyzed by zinc complexes 1-2.

When $5 \mathrm{~mol} \%$ of complex 1 was used as the pre-catalyst at room temperature, it yielded $50 \%$ of the corresponding boronate ester after 24 hours through the hydroboration reaction (Table 1, entry 2). However, the yield increased to $99 \%$ when the reaction temperature was increased to $60^{\circ} \mathrm{C}$ and maintained for 15 hours (Table 1 entry 3 ). Moreover, $89 \%$ yield was obtained when 5 mol\% of complex 2 was used for 15 hours at $60^{\circ} \mathrm{C}$ (Table 1 entry 10). Notably, product formation from the same reaction mixture was low in the absence of either pre-catalyst, even at $90^{\circ} \mathrm{C}$ for 24 hours (Table 1 , entry 1 ). When the pre-catalyst loading was reduced to $2.5 \mathrm{~mol} \%$, we observed a significant decreased yield of $60 \%$ after 15 hours at $60{ }^{\circ} \mathrm{C}$ (Table 1 , entry 4). The reaction also proceeded smoothly and there was negligible change in the yield when organic solvents such as toluene and THF were used (Table 1, entries 5-6). A lower yield of the desired product was obtained when different zinc salts such as $\mathrm{ZnCl}_{2}, \mathrm{ZnBr}_{2}$, and $\mathrm{Zn}(\mathrm{OAc})_{2}$ were used as pre-catalysts (Table 1, entries 7-9).

Table 1. Screening of pre-catalyst 1 for hydroboration of benzophenone.

\begin{tabular}{lllllll}
\hline Entry & $\begin{array}{l}\text { Pre- } \\
\text { catalysts }\end{array}$ & $\begin{array}{l}\text { Pre-cat. } \\
\text { loading } \\
(\mathrm{mol} \%)\end{array}$ & Solvent & $\begin{array}{l}\text { Temp. } \\
\left({ }^{\circ} \mathrm{C}\right)\end{array}$ & $\begin{array}{l}\text { Time } \\
(\mathrm{h})\end{array}$ & $\begin{array}{l}\text { Yield } \\
(\%)\end{array}$ \\
\hline 1 & None & - & Neat & 90 & 24 & 32 \\
2 & 1 & 5 & Neat & r.t. & 24 & 50 \\
3 & 1 & 5 & Neat & 60 & 15 & 99 \\
4 & 1 & 2.5 & Neat & 60 & 15 & 60 \\
5 & 1 & 5 & Tol & 60 & 12 & 95 \\
6 & 1 & 5 & THF & 60 & 15 & 96 \\
7 & $\mathrm{ZnCl}_{2}$ & 5 & Neat & 60 & 15 & 75 \\
8 & $\mathrm{Zn}(\mathrm{OAc})_{2}$ & 5 & Neat & 60 & 15 & 70 \\
9 & $\mathrm{ZnBr} 2$ & 5 & Neat & 60 & 15 & 72 \\
10 & 2 & 5 & Neat & 60 & 15 & 89 \\
11 & $\mathrm{Zn}(\mathrm{OTf})_{2}$ & 5 & Neat & 60 & 15 & 72 \\
\hline
\end{tabular}

Reaction conditions: Pre-catalyst $(5 \mathrm{~mol} \%)$, HBpin (1 mmol) followed by benzophenone $(1 \mathrm{mmol})$ at specified conditions. ${ }^{a}$ Yields were calculated based on ${ }^{1} \mathrm{H}$ NMR integration of characteristic product peak using $20 \mathrm{~mol} \%$ of 1,3,5-trimethoxybenzene as an internal standard.
Thus, with $60^{\circ} \mathrm{C}$ and neat conditions as optimal conditions, we set out to examine the scope of substrates using a series of ketones and HBpin in the presence of $5 \mathrm{~mol} \%$ of zinc pre-catalyst 1. Results of the catalytic hydroboration reaction are set out in Table 2. All the products obtained were analyzed using the NMR spectrum in the presence of $20 \mathrm{~mol} \%$ 1,3,5-trimethoxybenzene as the internal standard.

Table 2. Substrate scope of zinc complex 1-catalyzed hydroboration of ketones.

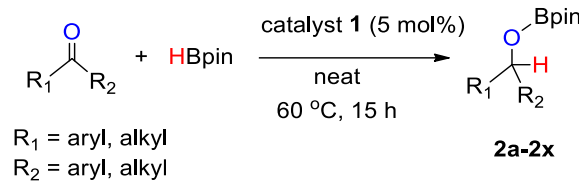

Entry Substrate<smiles>CCC(=O)c1ccccc1</smiles><smiles>[Z20]C1(C)OB2OC(C)(C)C(C)(O2)O1</smiles><smiles>CC(=O)c1ccc(C)cc1</smiles><smiles>CC(=O)c1ccc(CC(C)C)cc1</smiles><smiles>[Z60]C1(C)OB(OC(C)c2ccc(CC(C)C)cc2)OC1(C)C</smiles><smiles>COc1ccc(C(C)=O)cc1</smiles><smiles>[Z7]C(C)(C)C1(C)OB(OC(C)c2ccc(OC)cc2)OC1(C)C</smiles><smiles>CC(=O)c1ccc(F)cc1</smiles><smiles>CC(=O)c1ccccc1Cl</smiles><smiles>[Z2]C[C@H]1OB(OC(C)c2ccc(F)cc2)O[C@@H]1C</smiles><smiles>CC(=O)c1ccc(Br)cc1</smiles>

10<smiles>CC(=O)c1ccc([N+](=O)[O-])cc1</smiles><smiles>CC(OB1OC(C)(C)C(C)(C(C)(C)C)O1)c1ccc(Br)cc1</smiles>

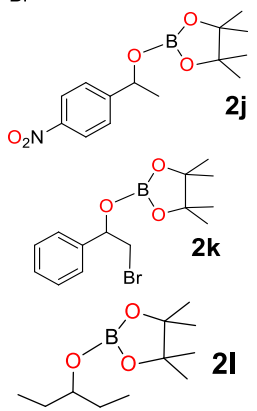


13<smiles>CCCCC(C)=O</smiles><smiles>O=C1CCCC1</smiles>

15<smiles>O=C1CCCCC1</smiles>

16<smiles>O=C1CCCc2ccccc21</smiles>

17<smiles>CC(=O)c1ccc2ccccc2c1</smiles>

18<smiles>CC(=O)c1ccncc1</smiles>

19<smiles>O=C(C(=O)c1ccccc1)c1ccccc1</smiles><smiles>O=C1C(=O)c2ccccc2-c2ccccc21</smiles>

21<smiles>CC(=O)c1cccc(N)c1</smiles>

22<smiles>CC(=O)c1ccc(C#N)cc1</smiles>

23<smiles>O=C(/C=C/c1ccccc1)c1ccccc1</smiles>

24<smiles>CC(=O)/C=C/c1ccccc1</smiles>

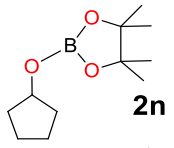

Traces

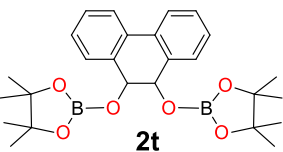<smiles>[Z14]C1(C)OB(OC(C)c2cccc(N)c2)OC1(C)C</smiles>

aryl ring with HBpin also showed excellent reactivities in the formation of corresponding boronate esters $\mathbf{2} \mathbf{g}-\mathbf{- 2 k}$ under optimum conditions, indicating the high efficiency of zinc precatalyst 1 toward ketone hydroboration (Table 2, entries 7-11). The aliphatic ketones, 3-pentanone, and 2-hexanone, and cyclic ketones (such as cyclopentanone, cyclohexanone, and tetralone) were also easily converted to the corresponding hydroborated products $2 \mathbf{I}-2 \mathbf{p}$ with yields of up to $99 \%$, without any difficulty (Table 2, entries 12-16). The substrate 2-acetylnapthalene and heterocyclic ketones such as 4-acetyl pyridine were also tested and nearly quantitative yields of the desired products $2 q-2 r$ were achieved under optimum reaction conditions (Table 2, entries 1718). Even the hydroboration reaction of a diketone such as benzyl was successfully converted to its respective diboronate esters $2 \mathbf{s}$, phenanthrenequinone did not give the respective boronate ester under optimal condition (Table 2, entries 19-20).

Further, to examine the chemoselectivity of zinc-catalyzed hydroboration reaction of carbonyl compounds, we employed various substrates such as 3-aminoacetophenone, 4acetylbenzonitrile, chalcone, and benzylideneacetone using complex 1 . The catalyst selectively reduced the ketone functional groups over other functional groups such as nitrile, and alkene that exhibited exclusive reactivity of ketones, and we observed the product formation $\mathbf{2 v - 2 x}$ up to $98 \%$ conversion (Table 2, entries 21-24).

Table 3. Substrate scope of zinc complex 1-catalyzed hydroboration of aldehydes.

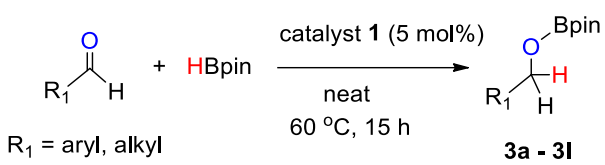

Entry Substrate<smiles>O=Cc1ccc(Cl)cc1</smiles><smiles>O=Cc1c(Cl)cccc1Cl</smiles>

6<smiles>O=Cc1ccccc1[N+](=O)[O-]</smiles>

7<smiles>O=Cc1cccc(Oc2ccccc2)c1</smiles><smiles>CC1(C)OB(OCc2ccc(Cl)cc2)OC1(C)C</smiles><smiles>CC1(C)OB(OCc2c(Cl)cccc2Cl)OC1(C)C</smiles>
functional groups such as methyl, isobutyl, and methoxy groups attached to the aromatic center within 15 hours (Table 2, entries 4-6). Reactions of the substrates with electron-withdrawing groups (such as fluoro-, chloro-, bromo-, and nitro- groups) of the version of ketones to their corresponding boronate esters $(2 a$ 2c) quantitatively (Table 2, entries 1-3). Boronate esters 2d-2 were obtained smoothly from the ketones with electron-donating 


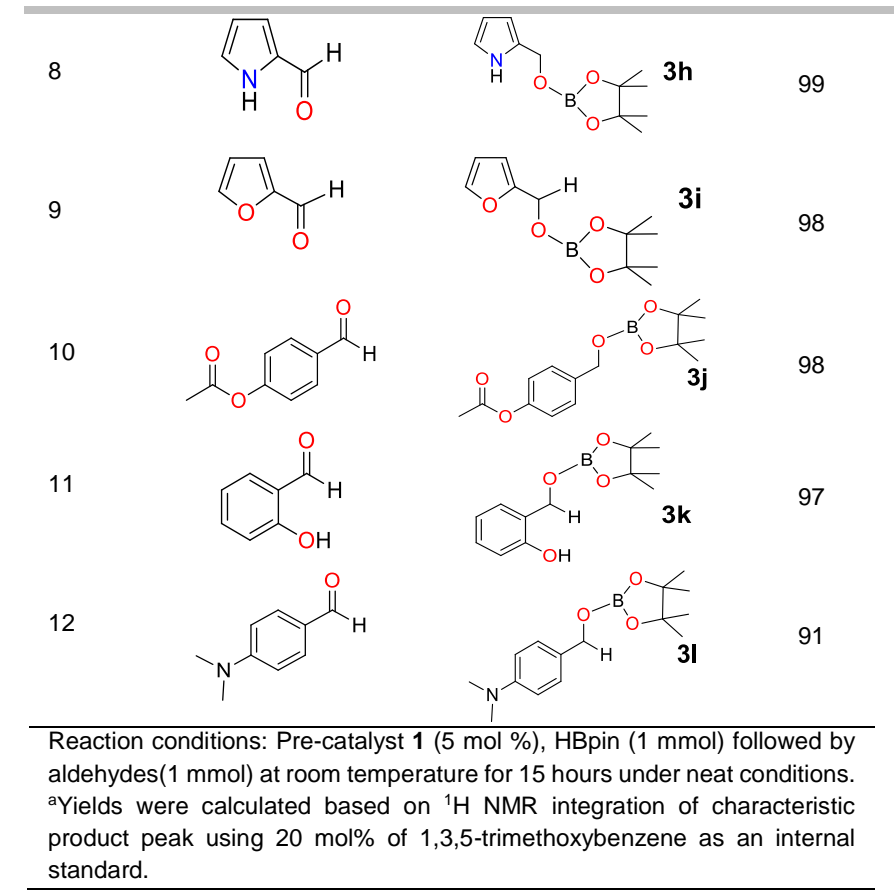

Zinc complex 1 plays a key role in the hydroboration of ketones. We were also interested in evaluating its catalytic efficiency in the hydroboration of aldehydes. As expected, benzaldehyde was converted to the boronate ester through the reaction with HBpin at room temperature in the presence of pre-catalyst $\mathbf{1}$ under neat conditions (Table 3 , entry 1 ). After the benchmark reaction of unsubstituted benzaldehyde as the substrate, we employed a range of aryl as well as heterocyclic aldehydes with electronwithdrawing and electron-donating groups for the desired hydroboration reactions at room temperature. The reaction between HBpin and 4-methoxybenzaldehyde afforded a quantitative yield within 15 hours of reaction time (Table 3, entries 2). Similarly, the reaction of substituted fluoro-, chloro-, dichloro-, and nitro-benzaldehyde with HBpin smoothly afforded a nearquantitative yield of the corresponding boronate (Table 3 , entries 3-6). 3-phenoxybenzaldehyde and heterocyclic aldehydes such as pyrrole-2-carboxaldehyde and furan-2-carboxaldehyde were quantitatively converted to the desired products under optimum conditions (Table 3 , entries 7-9). A yield of up to $98 \%$ of products 3j, 3k, and $\mathbf{3}$ l with good functional group tolerance was achieved when 4-formylphenylacetate, salicylaldehyde, and 4-N,Ndimethylaminobenzaldehyde were used as substrates to react with HBpin in the presence of the zinc pre-catalyst (1) (Table 3, entries 10-12).

Table 4. Hydrolysis of boronate esters to achieve corresponding primary alcohols.

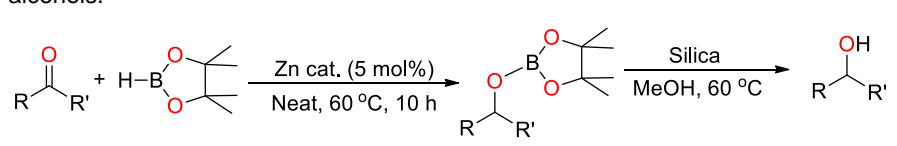<smiles>OC(c1ccccc1)c1ccccc1</smiles>
$2 a^{\prime}, 90 \%$<smiles>CC(O)c1ccc(F)cc1</smiles>

$2 g^{\prime}, 90 \%$<smiles>CC(O)c1ccccc1</smiles>

$2 b^{\prime}, 92 \%$<smiles>CC(O)c1ccccc1Cl</smiles>

$2 h^{\prime}, 88 \%$<smiles>Cc1ccc(C(C)O)cc1</smiles>

2d', 93\%<smiles>CC(O)c1ccc(Br)cc1</smiles>

$2 i^{\prime}, 89 \%$<smiles>COc1ccc(C(C)O)cc1</smiles>

$2 f^{\prime}, 93 \%$
Reaction conditions: Aldehyde/ketone $(1 \mathrm{mmol})$ and HBpin $(1 \mathrm{mmol})$ were stirred together for 15 hours in the presence of pre-catalyst $1(5 \mathrm{~mol} \%) 60^{\circ} \mathrm{C}$. Isolated yields and products were purified by column chromatography.

Further, the selected boronate esters were hydrolyzed to their corresponding alcohols using silica and methanol and in all cases we obtained near-quantitative yields (Figures FS 114-128). The results are summarized in Table 4.

\section{Reductive amination of aldehydes with primary amines.}

The one-pot reaction of aldehydes and ketones with amines, in the presence of a reducing agent, which is known as reductive amination, has wide application in the synthesis of various biologically active molecules. ${ }^{25}$ Well-known reducing agents such as hydrogen, sodium, lithium, tetrabutylammonium borohydrides, sodium cyanoborohydride, and sodium triacetoxyborohydride are often utilized for the reduction of carbonyl groups. However, most of these procedures have certain drawbacks and amine-borane compounds such as pyridineborane, ${ }^{26}$ 2-picoline-borane, ${ }^{27}$ dimethylamine-borane, ${ }^{28} \mathrm{~N}$-isopropyl- $\mathrm{N}$-methyl-tert-butylamineborane, ${ }^{29}$ 5-ethyl-2-methylpyridine-borane, ${ }^{30}$ and benzylamineborane $^{31}$ are used as safe and non-toxic alternative reducing agents for this purpose. We desired to explore utilizing zinc precatalyst 1 for the one-pot reductive amination of aldehydes and ketones with primary amines using HBpin as a reducing agent.

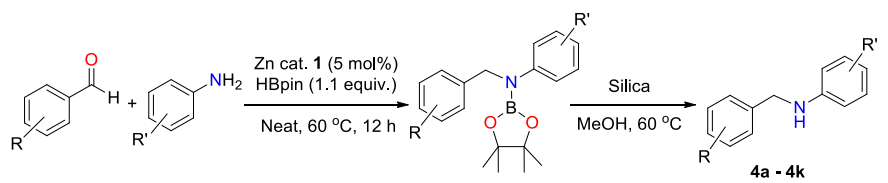

Scheme 3. Reductive amination of aldehydes with primary amines using zinc complex 1 as a pre-catalyst.

Table 5. Substrate scope of zinc complex 1-catalyzed reductive amination of aldehydes with primary amines.

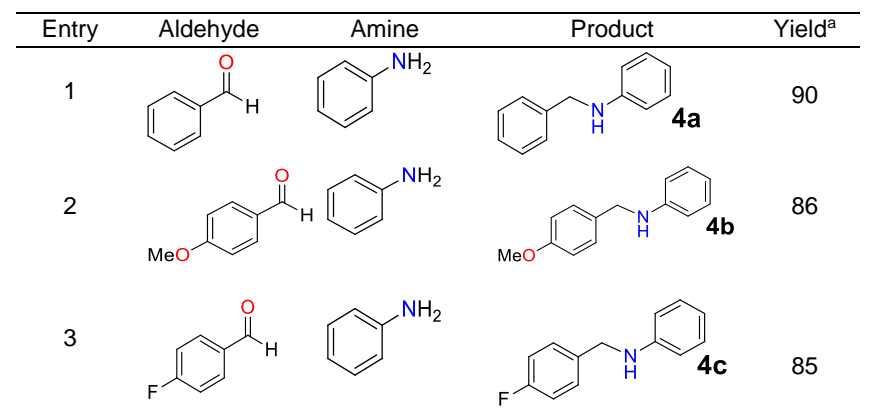




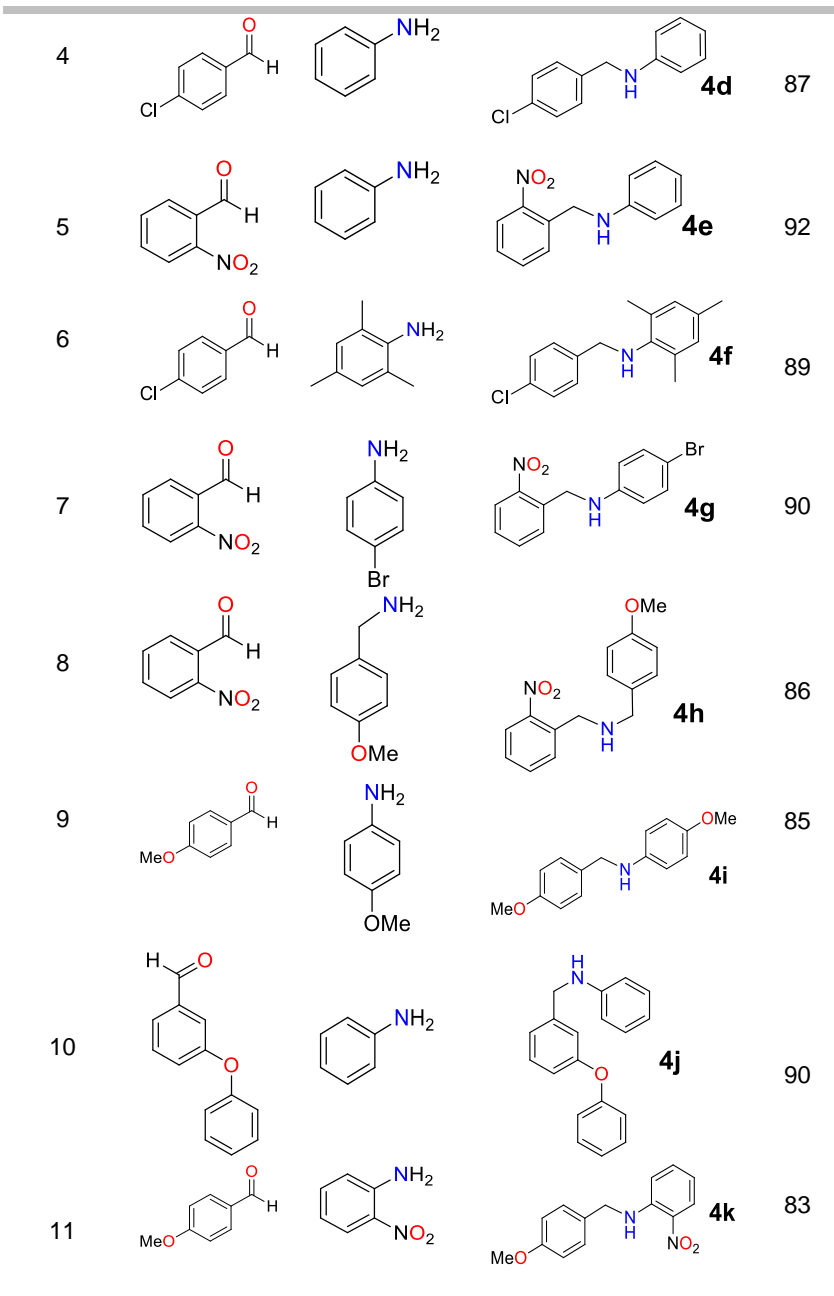

Reaction conditions: Pre-catalyst 1 (5 mol \%), HBpin (1.1 eq.) followed by aldehydes (1 eq.), and amines ( 1 eq.) at $60^{\circ} \mathrm{C}$ for 12 hours under neat condition. The hydroborated products were hydrolyzed with silica gel in methanol at $60^{\circ} \mathrm{C}$ for $6 \mathrm{~h}$. ${ }^{\text {al }}$ solated yields.

The reductive amination of aldehydes and primary amines in variable steric and electronic environments was carried out using zinc complex 1 as the pre-catalyst in neat condition with a low catalyst loading of $5 \mathrm{~mol} \%$ to give an excellent yield of the secondary amine within 12 hours (Scheme 3 ). The results are set out in Table 5. The reaction of benzaldehyde and aniline in the presence of HBpin and catalyst 1 afforded the corresponding boryl amine, which upon hydrolysis yielded $90 \%$ of $\mathrm{N}$ benzylaniline $4 a$ (Table 5 , entry 1 ). The catalytic reaction of electron-rich 4-methoxybenzylamine and aniline afforded the corresponding $\mathrm{N}$-benzylaniline $\mathbf{4 b}$ in $86 \%$ yield (Table 5 , entries 2).

Similar reactions between aldehydes with electron-withdrawing groups (such as fluoro-, chloro-, and nitro-benzaldehyde) and HBpin and catalyst 1 proceeded without difficulty to produce the corresponding $\mathrm{N}$-benzylanilines $\mathbf{4 c - 4 e}$ in yields of $85-92 \%$ (Table
5, entries 3-5). The sterically bulky mesitylamine and 4chlorobenzaldehyde were smoothly converted to 2,4,6-trimethyl$\mathrm{N}$-(4-methylbenzyl)aniline (4f) in $89 \%$ yield under optimum conditions (Table 5, entry 6 ). Deactivated nitro-benzaldehydes also reacted with aniline and benzylamine in the presence of HBpin and zinc catalyst $\mathbf{1}$ to give corresponding amines $\mathbf{4 g}$ and 4h respectively in high yields (Table 5, entries $7-8$ ). Secondary amines $\mathbf{4 i - 4 k}$ were also obtained in good yields from the catalytic reactions of respective aldehyde and arylamine substrates under optimum conditions (Table 5, entries 9-11), indicating the efficiency of the current protocol using the zinc catalyst.

\section{Computational Study}

Density functional theory (DFT) calculations were performed to develop mechanisms for $\left[\kappa^{2}-\left(\mathrm{PyCH}=\mathrm{NCPh}_{3}\right) \mathrm{ZnCl}_{2}\right](\mathbf{1})$-catalyzed hydroboration of carbonyl compounds in the presence of HBpin. We built a computational model of catalyst $\mathbf{1}$ without any truncation (Figure 4). Acetophenone is taken as a carbonyl substrate in the calculations. DFT computations were carried out using the ORCA4.2 computational chemistry package. ${ }^{32}$ The relative Gibbs free energies reported in mechanistic studies were obtained at the BP86 $33,34-D 3^{35} /$ def2-TZVP36//BP86-D3/def2$\mathrm{SVP}^{36}$ levels of DFT. Refer to the supporting information for all computational details. Gibbs free energies $\left(\mathrm{kcal} \mathrm{mol}^{-1}\right)$ reported in mechanistic studies were calculated at $333 \mathrm{~K}$ and are relative to 1.

(a)

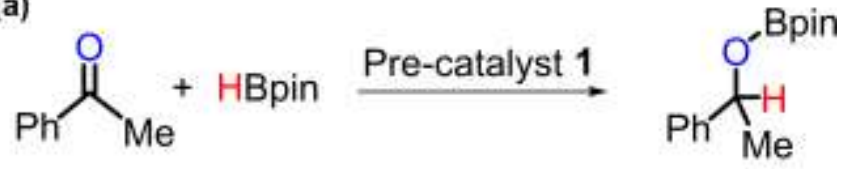

(b)

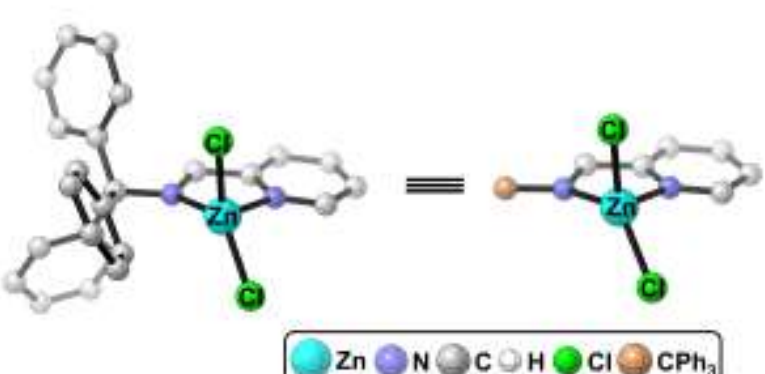

Figure 4. (a) Hydroboration of acetophenone in presence of pre-catalyst 1 and HBpin. (b) Computational model of $\left[\kappa^{2}-\left(\mathrm{PyCH}=\mathrm{NCPh}_{3}\right) \mathrm{ZnCl}_{2}\right](\mathbf{1})$, in which all the phenyl hydrogens are omitted to enhance the visual clarity.

Mechanism-1: In the first step, pre-catalyst $\mathbf{1}$ and acetophenone combine to give $\mathbf{B}$ in which $\mathrm{Zn}$ is loosely bound to $\mathrm{O}$ (of acetophenone) ( $d_{\mathrm{zn}-\mathrm{O}}: 2.32 \AA$ ) (Figure 5). Next, B reacts with HBpin to generate a $\mathrm{B}$ (HBpin)-O(acetophenone) bond and results to an intermediate $\mathbf{C}$. In the subsequent step, $\mathbf{C}$ undergoes a hydride transfer from boron(HBpin) to the electrophilic carbon of 


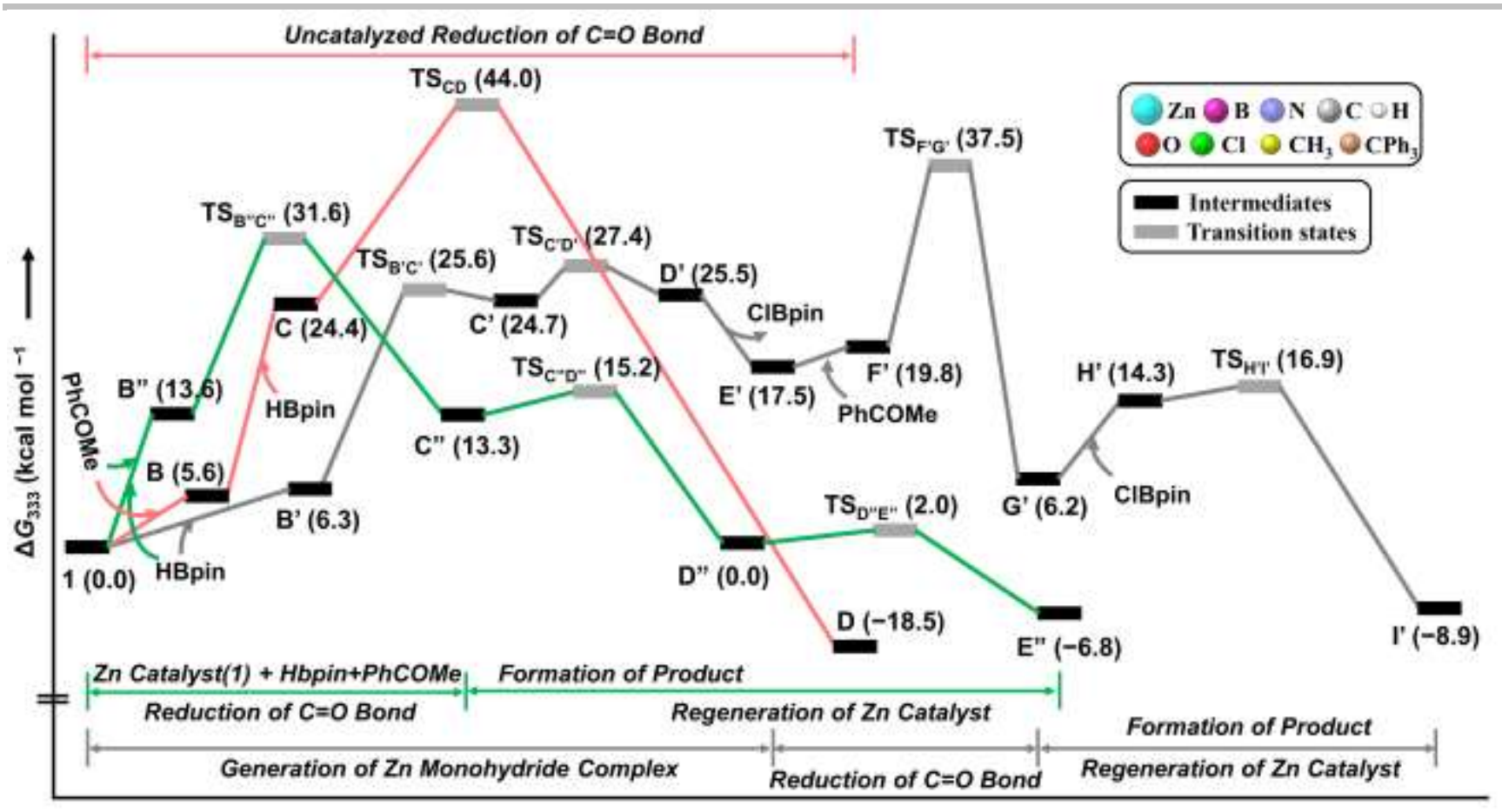

Mechanism-1

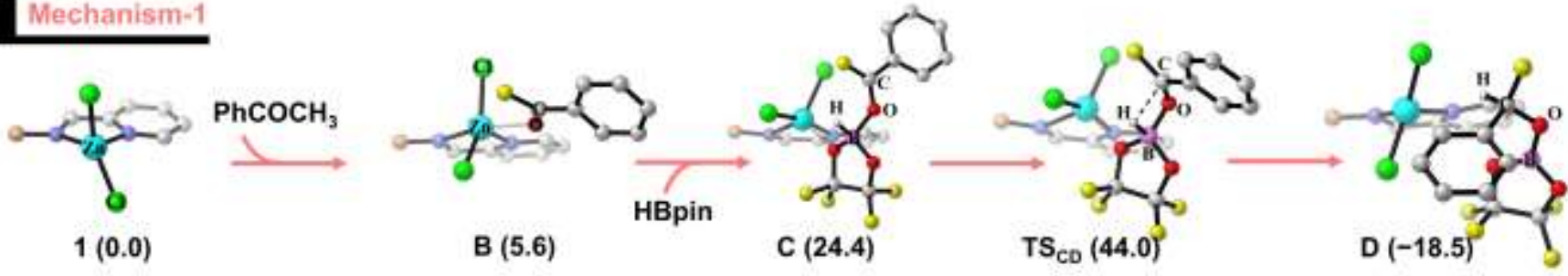

Mechanism-2

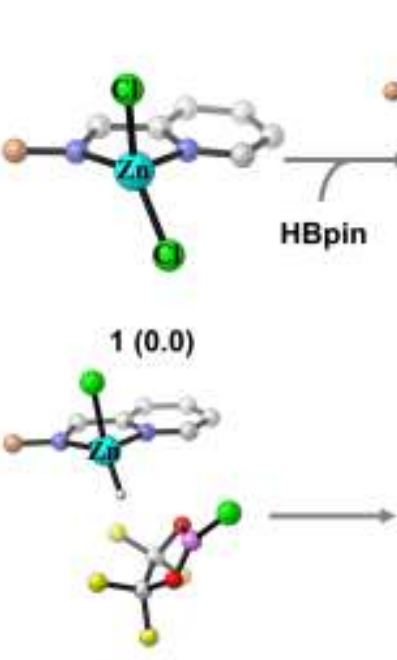

D' (25.5)

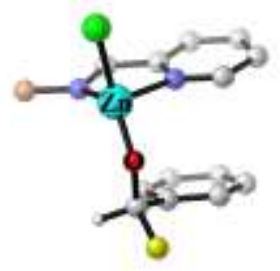

G' (6.2)
$\mathrm{TS}_{\mathrm{CD}}(44.0)$
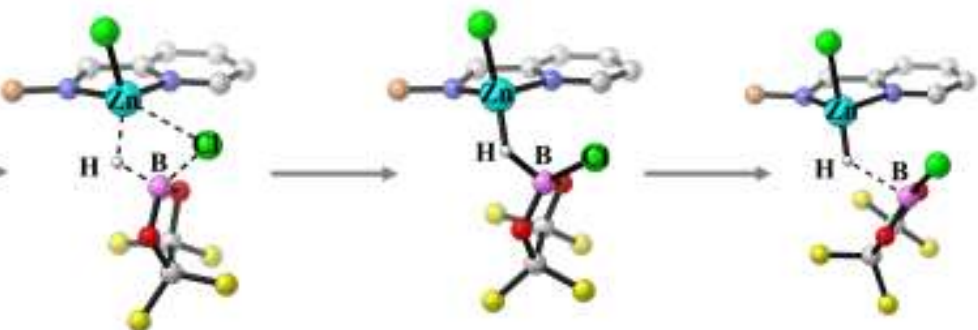

$\mathrm{TS}_{\mathrm{B}^{\prime} \mathrm{C}^{\prime}}(25.6)$

C' (24.7)

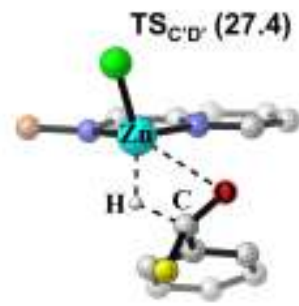

E' (17.5)

$F^{\prime}(19.8)$

$\mathrm{TS}_{\mathrm{FG}}$ (37.5)

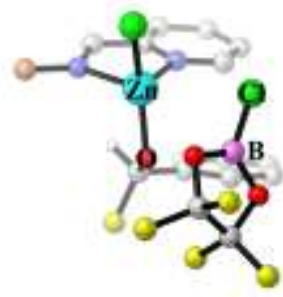

H' (14.3)

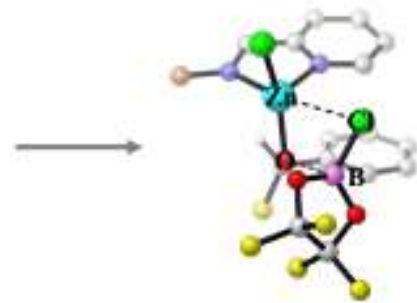

$\mathrm{TS}_{\mathrm{HT}}(16.9)$

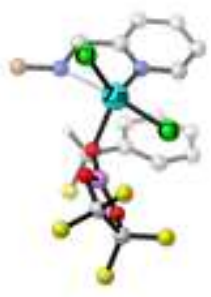

I' (-8.9) 


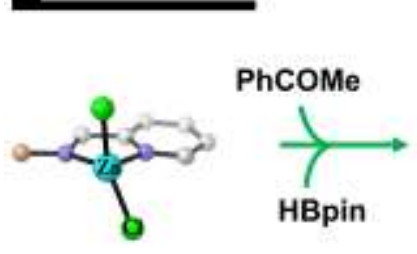

$1(0.0)$

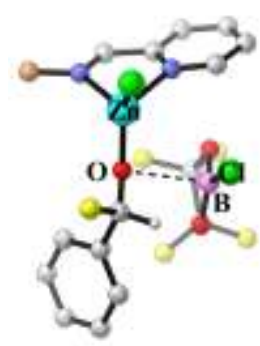

$\mathrm{TS}_{\mathrm{C}^{\prime \prime \mathrm{D}^{*}}}$ (15.2)

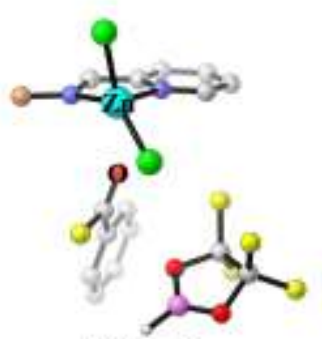

B" (13.6)

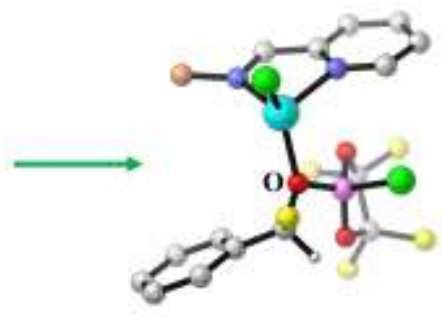

D" $(0.0)$

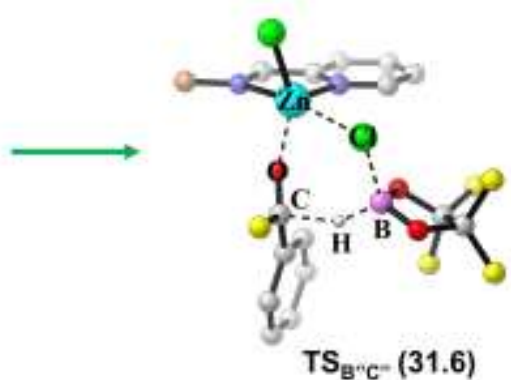

$\mathrm{TS}_{\mathrm{B}^{\mathrm{C}} \mathrm{C}^{-}}$(31.6)

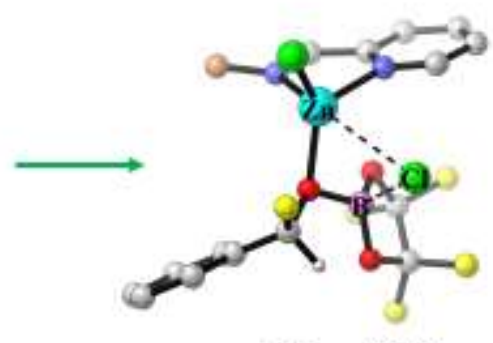

$\mathrm{TS}_{\mathrm{D}^{\text {"E" }}}$ (2.0)

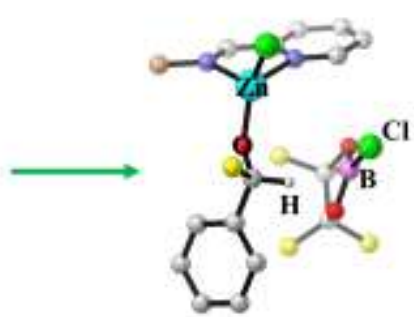

C" (13.3)

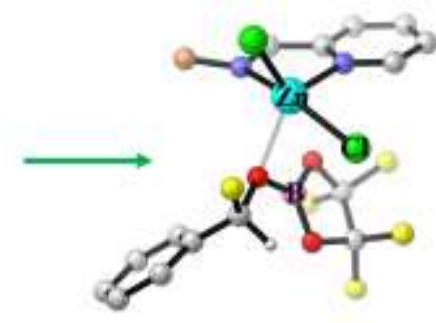

$E^{\prime \prime}(-6.8)$

Figure 5. DFT-derived pathways for hydroboration of acetophneone (i) Mechanism-1: No role of zinc pre-catalyst, (ii) Mechanism-2: Through zinc-monohydride complex (E'), (iii) Mechanism-3: Avoiding the route of zinc-monohydride complex (E'). The DFT method used in the study is BP86-D3/def2-TZVP//BP86-D3/def2SVP. Gibbs free energies $\Delta \mathrm{G}_{333}\left[\mathrm{kcal} \mathrm{mol}^{-1}\right]$ are relative to $\mathbf{1}$.

acetophenone via a transition state $\left(\mathbf{T S}_{\mathrm{CD}}\right)$ with an overall activation barrier of $44.0 \mathrm{kcal} \mathrm{mol}^{-1}$ to yield a highly exoergic intermediate $\mathbf{D}$. In $\mathbf{T S} \mathbf{c D}$, since $\mathrm{Zn}$ is far away from the reaction site where the hydride transfer occurs, pre-catalyst 1 does not play an active role in this mechanism. Therefore, this prompted us to investigate alternative pathways where pre-catalyst 1 can participate in the mechanism. In the following discussion, we present such two mechanisms.

Mechanism-2: In the initial step, pre-catalyst $\mathbf{1}$ is added with HBpin to form B', which undergoes a concerted hydride-chloride exchange between the boron and zinc centers via TS $_{\mathbf{B}^{\prime}} \mathbf{C}^{\prime}$, with an overall activation barrier of $25.6 \mathrm{kcal} \mathrm{mol}^{-1}$ to yield an unstable intermediate C' (Figure 5). In the subsequent steps, C' readily dissociates to the zinc-monohydride complex (E') and Cl-Bpin. Next, E' acts as a hydride source to reduce the incoming acetophenone to yield $\mathbf{G}$ ' via a transition state $\mathbf{T S}_{\mathbf{F}} \mathbf{G}^{\prime}$, with an overall activation barrier of $37.5 \mathrm{kcal} \mathrm{mol}^{-1}$. In $\mathbf{G}^{\prime}$, zinc and oxygen are bound through a strong sigma bond $\left(d_{z n-0}: 1.88 \AA\right)$, thus yielding a significantly stable species compared to its preceding intermediate. G' finally reacts with Cl-Bpin to form I' which contains the hydroborated product and $\mathbf{1}$ (Figure 5). An alternate pathway is also possible from G' when it reacts with $\mathrm{H}$-Bpin in place of $\mathrm{Cl}$-Bpin. However, this route is energetically less favorable and discussed in detail in supporting information. (Figure FS151).

In brief, our computational studies show that the mechanism-2 is preferred over the mechanism- 1 by $6.5 \mathrm{kcal} \mathrm{mol}^{-1}\left(\mathbf{T S}_{\mathbf{F}^{\prime} \mathbf{G}^{\prime}}\right.$ vS $\mathbf{T S} \mathrm{CD}$ ) However, the mechanism-2 is not experimentally supported as this mechanism goes via a zinc-monohydride complex (E') and such an intermediate could not be detected in our experiments. Thus, we looked for alternative routes to avoid the formation of E'.

Mechanism-3: In the first step, $\mathbf{1}$ is added with HBpin and acetophenone to get B" which undergoes a hydride transfer via a six-membered cyclic transition state $\mathbf{T S}_{\mathbf{B}}{ } \mathrm{C}$ " with an activation barrier of $18.0 \mathrm{kcal} \mathrm{mol}^{-1}$ (B" $\rightarrow \mathbf{T S}_{\mathrm{B}}$ "C) to produce C"' (Figure 5). TS $_{B}$ "C" is a concerted transition state representing three sequences: (i) nucleophilic attack of chloride to boron, (ii) hydride transfer from boron to the carbonyl carbon, and (iii) the $\mathrm{Zn}-\mathrm{O}$ bond formation. The subsequent $\mathbf{C}$ " $\rightarrow \mathrm{D}$ " transformation readily

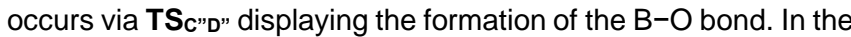
next step, D' leads to E'' (hydroborated product + pre-catalyst 1)

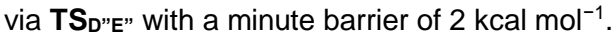

Here, we found that the mechanism- 3 is energetically lower than

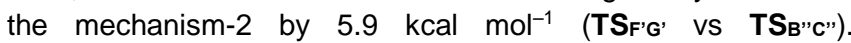
Mechanism-3 avoids the formation of the zinc monohydride complex E' which is also in agreement with our experiments. Moreover, our studies show that the hydroboration of acetophenone by zinc pre-catalyst 1 proceeds via a sixmembered transition state in which the zinc center is involved in transferring chloride and binding the reduced aldehyde moiety. Thus, the mechanism- 3 depicts the apparent role of $\mathrm{Zn}$ as a promoter in the reaction.

\section{Conclusion}

In summary, we have synthesized and structurally characterized iminopyridine-supported zinc complexes $\left[\kappa^{2}-(\mathrm{PyCH}=\mathrm{NR}) \mathrm{ZnX}_{2}\right]$ (1-2). The use of innocuous and bio-compatible zinc complex 1 as a competent pre-catalyst in the synthesis of a series of boronate ester compounds through chemoselective catalytic hydroboration of ketones and aldehydes, using a simple but highly efficient protocol, is described. Our DFT-based mechanistic studies of zinc-catalyzed hydroboration of carbonyl compounds conclude that a six-member concerted transition state $\mathbf{T S}_{\mathrm{B}}{ } \mathrm{C}$ " is a key stationary point in the potential energy surface which depicts two important points: (i) the zinc monohydride is not an intermediate in the reaction and (ii) zinc plays an active role in the 
reaction. We further conclude that the rate-determining step (RDS) via TS B"C " combines three steps in a concerted fashion: (i) transfer of chloride to boron, (ii) reduction of carbonyl group and (iii) the $\mathrm{Zn}-\mathrm{O}$ bond formation. The overall energy barrier required to cross the RDS is $31.6 \mathrm{kcal} \mathrm{mol}^{-1}$. This protocol implies facile and atom-economical access to boronate esters as precursors to the synthesis of corresponding alcohol. Good functional group tolerance and economic viability of the zinc pre-catalyst make it one of the most versatile alternatives in the hydroboration of carbonyl compounds. The neutral coordination of carbonyl oxygen to the Lewis-acidic zinc metal center is proposed as the most plausible mechanism.

\section{Experimental Section}

\section{General consideration}

All manipulations involving air- and moisture-sensitive compounds were carried out under argon using the standard Schlenk technique or argonfilled M. Braun glove box. Hydrocarbon solvent ( $n$-hexane) was distilled under a nitrogen atmosphere from $\mathrm{LiAlH}_{4}$ and stored inside the glove box. The solvent dichloromethane and methanol were freshly distilled. ${ }^{1} \mathrm{H}$ NMR $(400 \mathrm{MHz})$, and ${ }^{13} \mathrm{C}\left\{{ }^{1} \mathrm{H}\right\}(100 \mathrm{MHz})$ spectra were recorded on the BRUKER ADVANCE III-400 spectrometer. Pyridine-2-carboxaldehyde, 2,6diisopropylaniline, and tritylamine were purchased from TCl Chemicals (India) Pvt. Ltd and transferred to the glove box and used without any further purification. All aldehydes, ketones, and HBpin were purchased from Sigma Aldrich, Alfa Aesar, or TCl Chemicals (India) Pvt. Ltd and stored in the glove box and used as received. NMR solvent $\left(\mathrm{CDCl}_{3}\right.$ and DMSO-d $d_{6}$ ) were purchased from Merck and distilled over molecular sieves.

Synthesis of Ligand [PyCH=NCPh ] (L1). To a Schlenk flask, pyridine2-carboxaldehyde $(0.499 \mathrm{~g}, 4.66 \mathrm{mmol})$ and tritylamine $(1.208 \mathrm{~g}, 4.66$ $\mathrm{mmol}$ ) were added in the presence of a catalytic amount of glacial acetic acid in methanol at room temperature for 12 hours. The precipitate was then filtered and washed with methanol to obtain the product. Yield: 1.267 $\mathrm{g}(78 \%) .{ }^{1} \mathrm{H} \mathrm{NMR}\left(400 \mathrm{MHz}, \mathrm{CDCl}_{3}\right): \delta_{\mathrm{H}}(\mathrm{ppm}) 8.61-8.60(\mathrm{~d}, J=2 \mathrm{~Hz}, 1 \mathrm{H}$, Ar- $H$ ), $8.40-8.38(\mathrm{~d}, J=4 \mathrm{~Hz}, 1 \mathrm{H}, \mathrm{Ar}-\mathrm{H}), 7.99(\mathrm{~s}, 1 \mathrm{H}, \mathrm{CH}), 7.82-7.78(\mathrm{t}$, $J=8 \mathrm{~Hz}, 1 \mathrm{H}, \mathrm{Ar}-H), 7.34-7.23(\mathrm{~m}, 16 \mathrm{H}, \mathrm{Ar}-\mathrm{H}) .{ }^{13} \mathrm{C}\left\{{ }^{1} \mathrm{H}\right\}$ NMR $(100 \mathrm{MHz}$, $\mathrm{CDCl}_{3}$ ): $\delta \mathrm{c}(\mathrm{ppm}) 161.1,155.4,149.3,145.4,136.8,129.9,127.9,127.1$, 124.9, 121.5. Elemental Analysis: $\mathrm{C}_{25} \mathrm{H}_{20} \mathrm{~N}_{2}$ (348.4): Calcd. C 86.17, H 5.79 , N 8.04. Found C 85.82, H 5.69, N 7.87 .

Synthesis of [PyCH=NDipp] (L2). In a Schlenk flask, pyridine-2carboxaldehyde $(0.302 \mathrm{~g}, 2.82 \mathrm{mmol})$ and 2,6-diisopropylaniline $(0.5 \mathrm{~g}$, $2.82 \mathrm{mmol}$ ) were taken in the presence of a catalytic amount of acetic acid in methanol and heated to reflux for 10 hours. The solvent was then evaporated to dryness and the product was recrystallized from methanol. Yield: $0.743 \mathrm{~g}(95 \%) .{ }^{1} \mathrm{H}$ NMR $\left(400 \mathrm{MHz}, \mathrm{CDCl}_{3}\right): \delta_{\mathrm{H}}(\mathrm{ppm}) 8.74-8.73$ (d, $J=2 \mathrm{~Hz}, 1 \mathrm{H}, \mathrm{Ar}-H), 8.32(\mathrm{~s}, 1 \mathrm{H}, \mathrm{CH}), 8.29-8.27(\mathrm{~d}, J=4 \mathrm{~Hz}, 1 \mathrm{H}, \mathrm{Ar}-\mathrm{H})$, $7.87-7.83(\mathrm{t}, J=8 \mathrm{~Hz}, 1 \mathrm{H}, \mathrm{Ar}-H), 7.43-7.39(\mathrm{~m}, 1 \mathrm{H}, \mathrm{Ar}-\mathrm{H}), 7.19-7.11$ (m, 3H, Ar-H), $3.03-2.92$ (sept, $J=7.33 \mathrm{~Hz}, 2 \mathrm{H}, \mathrm{Ar}-H$ ), $1.19-1.17$ (d, $J=$ $\left.4 \mathrm{~Hz}, 12 \mathrm{H}, \mathrm{CH}_{3}\right) \cdot{ }^{13} \mathrm{C}\left\{{ }^{1} \mathrm{H}\right\} \mathrm{NMR}\left(100 \mathrm{MHz}, \mathrm{CDCl}_{3}\right): \delta_{\mathrm{c}}(\mathrm{ppm}) 163.1,154.4$, $149.8,148.5,137.4,136.9,125.5,124.6,123.2,121.5,28.1,23.6$. Elemental Analysis: $\mathrm{C}_{18} \mathrm{H}_{22} \mathrm{~N}_{2}$ (266.4): Calcd. C 81.16, H 8.32, N 10.52. Found C 80.96, H 8.28, N 10.43 .

Synthesis of Zinc Complex (1). Ligand L1 $(0.697 \mathrm{~g}, 2 \mathrm{mmol})$ and anhydrous $\mathrm{ZnCl}_{2}(0.272 \mathrm{~g}, 2 \mathrm{mmol})$ were mixed in dichloromethane and stirred at room temperature for 12 hours. The precipitate was then filtered and washed with hexane to obtain the crude product. Complex 1 was recrystallized from toluene solution at $-35{ }^{\circ} \mathrm{C}$. Yield: $0.776 \mathrm{~g}(80 \%) .{ }^{1} \mathrm{H}$ NMR (400 MHz, DMSO-d 6 ): $\delta_{H} 8.60-8.59$ (d, $J=2 \mathrm{~Hz}, 1 \mathrm{H}, \mathrm{Ar}-H$ ), 8.33 $8.31(\mathrm{~d}, J=4 \mathrm{~Hz}, 1 \mathrm{H}, \mathrm{Ar}-H), 7.99-7.95$ (t, $J=10 \mathrm{~Hz}, 1 \mathrm{H}, \operatorname{Ar}-\mathrm{H}$ ), 7.77 (s, $1 \mathrm{H}, \mathrm{CH}), 7.52-7.49(\mathrm{~m}, 1 \mathrm{H}, \mathrm{Ar}-\mathrm{H}), 7.38-7.34(\mathrm{~m}, 6 \mathrm{H}, \mathrm{Ar}-\mathrm{H}), 7.31-7.28$ (m, 3H, Ar-H), $7.22-7.20(\mathrm{~m}, 6 \mathrm{H}, \mathrm{Ar}-\mathrm{H}) .{ }^{13} \mathrm{C}\left\{{ }^{1} \mathrm{H}\right\} \mathrm{NMR}(100 \mathrm{MHz}$, DMSO$\left.\mathrm{d}_{6}\right)$ : $\delta c(p p m) 160.8,154.1,149.5,145.0,137.3,129.2,128.1,127.1$,
125.7, 120.9. Elemental Analysis: $\mathrm{C}_{25} \mathrm{H}_{20} \mathrm{Cl}_{2} \mathrm{~N}_{2} \mathrm{Zn}$ (484.7): Calcd. C 61.95, H 4.16, N 5.78. Found C 61.75, H 4.03, N 5.68.

Synthesis of Zn-metal complex (2). Ligand L2 $(0.100 \mathrm{~g}, 0.375 \mathrm{mmol})$ and anhydrous $\mathrm{Znl}_{2}(0.119 \mathrm{~g}, 0.375 \mathrm{mmol})$ were mixed in dichloromethane and stirred at room temperature for 24 hours. The precipitate was then filtered to obtain the crude product. Complex 2 was recrystallized from a saturated solution of toluene at $-35^{\circ} \mathrm{C}$. Yield: $0.196 \mathrm{~g}(90 \%)$. ${ }^{1} \mathrm{H}$ NMR $(400$ $\left.\mathrm{MHz}, \mathrm{DMSO}-\mathrm{d}_{6}\right): \delta_{\mathrm{H}} 8.74(\mathrm{~s}, 1 \mathrm{H}, \mathrm{Ar}-\mathrm{H}), 8.31(\mathrm{~s}, 1 \mathrm{H}, \mathrm{CH}), 8.22-8.20(\mathrm{~d}$ $1 \mathrm{H}, \mathrm{Ar}-\mathrm{H}), 8.03(\mathrm{~s}, 1 \mathrm{H}, \mathrm{Ar}-\mathrm{H}), 7.62(\mathrm{~s}, 1 \mathrm{H}, \mathrm{Ar}-\mathrm{H}), 7.18-7.12(\mathrm{~m}, 1 \mathrm{H}, \mathrm{Ar}-\mathrm{H})$ $2.93-2.79$ (sept, $J=9.33 \mathrm{~Hz}, 2 \mathrm{H}, \mathrm{CH}), 1.11-1.10$ (d, $J=2 \mathrm{~Hz}, \mathrm{CH}_{3}$ ). ${ }^{13} \mathrm{C}\left\{{ }^{1} \mathrm{H}\right\}$ NMR (100 MHz, DMSO-d 6 ): $\delta_{c}$ (ppm) 163.3, 153.5, 149.8, 148.1, 137.4, 136.6, 126.1, 124.4, 122.9, 120.9, 27.5, 23.2. Elemental Analysis: $\mathrm{C}_{18} \mathrm{H}_{22} \mathrm{l}_{2} \mathrm{~N}_{2} \mathrm{Zn}$ (585.57): Calcd. C 36.92, H 3.79, N 4.78. Found C 36.83, H 3.66, N 4.65 .

\section{General procedure for hydroboration of aldehydes and ketones}

Hydroboration of aldehydes and ketones with HBpin was performed using the standard protocol. In the glove box, zinc complex $1(0.05 \mathrm{mmol})$ and the corresponding aldehyde or ketone $(1 \mathrm{mmol})$ were charged into a 25 $\mathrm{mL}$ Schlenk tube, which was followed by the addition of HBpin $(1 \mathrm{mmol})$ to the reaction mixture. The mixture was subjected to reactions specified in Tables 2 and 3 . The progress of the reaction was monitored from characteristic ${ }^{1} \mathrm{H}$ NMR resonance using 20 mol\% 1,3,5-trimethoxybenzene as the internal standard.

\section{General procedure reductive amination of aldehyde and ketones with primary amines}

Hydroboration of aldimines with HBpin was performed using the standard protocol. The aldehyde $(1 \mathrm{mmol})$ and amine $(1 \mathrm{mmol})$ were taken in a 25 $\mathrm{mL}$ Schlenk flask. Catalyst 1 (5 mol \%) was then added and the reaction mixture was stirred for 3 hours at room temperature. HBpin (1.1 eq.) was added to it and the reaction mixture was heated at $60{ }^{\circ} \mathrm{C}$ for 12 hours. After the specified time, a small quantity of silica and methanol were added and the reaction mixture was heated further at $60{ }^{\circ} \mathrm{C}$ for 6 hours for hydrolysis. The corresponding products obtained were isolated and purified using column chromatography.

\section{Supporting information summary}

Crystallographic data of $\mathbf{1}, \mathbf{2}$, and ${ }^{1} \mathrm{H}$ and ${ }^{13} \mathrm{C}\left\{{ }^{1} \mathrm{H}\right\}$ NMR spectra of hydroboration products, $\mathbf{2} \mathbf{a}-\mathbf{2} \mathbf{x}, \mathbf{3} \mathbf{a}-\mathbf{3 l}$, and $\mathbf{4 a - 4 k}$ are given in the electronic supporting information. Computational details are also given in electronic supporting information.

\section{Acknowledgments}

This work was supported by the Science and Engineering Research Board (SERB), Department of Science and Technology (DST), Government of India, under project no (EMR/2016/005150). RK thanks CSIR (09/1001(0048)/2019EMR-I) for his Ph.D. fellowship. PR thanks CSIR for the SRF fellowship (09/143(1001)/2019-EMR-I). PG acknowledges SERB (CRG/2021/000759) for financial support. Computational facilities to PG were provided by IIT Roorkee. We also sincerely thank to reviewers for their valuable comments to improve the manuscript.

Keywords: Aldehyde $\bullet$ Ketone $\cdot$ Hydroboration $・$ Zinc $・$ Reductive amination

[1]. X. Zeng, Chem. Rev. 2013, 113, 6864 and references cited therein

[2]. (a) D. H. Ma, A. K. Jaladi, J. H. Lee, T. S. Kim, W. K. Shin, H. Hwang, D. K. An, ACS Omega 2019, 4, 15893; (b) A. Harinath, J. Bhattacharjee, T. 
K. Panda, Adv. Synth. Catal. 2019, 361, 850; (c) C. Weetman, M. S. Hill, M. F. Mahon, Polyhedron 2016, 103, 115; (d) M. K. Barman, A. Baishya, S. Nembenna, Dalton Trans. 2017, 46, 4152; (e) S. Yadav, R. Dixit, M. K Bisai, K. Vanka, S. S. Sen, Organometallics 2018, 37, 4576; (f) M. K. Sharma, M. Ansari, P. Mahawar, G. Rajaraman, S. Nagendran, Dalton Trans. 2019, 48, 664; (g) I. Banerjee, A. Harinath, T. K. Panda, Eur. J. Inorg. Chem. 2019, 2019, 2224; (h) S. Das, H. Karmakar, J. Bhattacharjee, T. K. Panda, Dalton Trans. 2019, 48, 11978; (i) J. P. Abell, H. Yamamoto, J. Am. Chem. Soc. 2008, 130, 10521; (j) J. P. Stelmach C. A. Bange, R. Waterman, Dalton Trans. 2016, 45, 6204. (k) D. Yan, X Wu, J. Xiao, Z. Zhu, X. Xu, X. Bao, Y. Yao, Q. Shen, M. Xue, Org. Chem. Front. 2019, 6, 648; (I) Z. Zhu, X. Wu, X. Xu, Z. Wu, M. Xue, Y. Yao, Q. Shen, X. Bao, J. Org. Chem. 2018, 83, 10677.

[3]. (a) H. Zeng, J. Wu, S. Li, C. Hui, A. Ta, S. Y. Cheng, S. Zheng, G. Zhang, Org. Lett. 2019, 21, 401; (b) P. K. Verma, A. S. Sethulekshmi, K. Geetharani, Org. Lett. 2018, 20, 7840; (c) U. K. Das, C. S. Higman, B. Gabidullin, J. E. Hein, R. T. Baker, ACS Catal. 2018, 8, 1076; (d) J. B. Geri, N. K. Szymczak, J. Am. Chem. Soc. 2015, 137, 12808; (e) T. Zhang K. Manna, W. Lin, J. Am. Chem. Soc. 2016, 138, 3241; (f) A. Kaithal, B. Chatterjee, C. Gunanathan, Org. Lett. 2015, 17, 4790; (g) A. Harinath, J. Bhattcharjee, K. R. Gorantla, B. S. Mallik, T. K. Panda, Eur. J. Org. Chem. 2018, 2018, 3180; (i) I. Banerjee, S. Anga, K. Bano, T. K. Panda, J. Organomet. Chem. 2019, 902, 120958; (j) J. Bhattacharjee, A. Harinath, K. Bano, T. K. Panda, ACS Omega 2020, 5, 1595; (k) J. Bhattacharjee, A. Harinath, I. Banerjee, H. P. Nayek, T. K. Panda, Inorg. Chem. 2018, $57,12610$.

[4]. (a) D. Yan, P. Dai, S. Chen, M. Xue, Y. Yao, Q. Shen, X. Bao, Org. Biomol. Chem. 2018, 16, 2787; (b) W. Wang, X. Shen, F. Zhao, H. Jiang, W. Yao, S. A. Pullarkat, L. Xu, M. Ma, J. Org. Chem. 2018, 83, 69; (c) M. M. Basiouny, J. A. Schmidt, Organometallics 2017, 36, 721; (d) C. J. Barger, R. D. Dicken, V. L. Weidner, A. Motta, T. L. Lohr, T. J. Marks, J. Am Chem. Soc. 2020, 142, 8019; (e) Y. A. Rina, J. A. Schmidt, Organometallics 2019, 38, 4261; (f) J. Liu, W. Chen, J. Li, C. Cui, ACS Catal. 2018, 8, 2230.

[5]. (a) H. Liu, M. Khononov, M. S. Eisen, ACS Catal. 2018, 8, 3673; (b) T. Ghatak, K. Makarov, N. Fridmana, M. S. Eisen, Chem. Commun. 2018 54, 11001; (c) H. Liu, K. Kulbitski, M. Tamm, M. S. Eisen, Chem. Eur. J 2018, 24, 5738; (d) S. Saha, M. S. Eisen, ACS Catal. 2019, 9, 5947-5956.

[6]. (a) G. Psomas, D. P. Kessissoglou, Dalton Trans. 2013, 42, 6252; (b) T. J. Khoo, M. K. bin Break, K. A. Crouse, M. I. M. Tahir, A. M. Ali, A. R. Cowley, D. J. Watkin, M. T. H. Tarafder. Inorg. Chim. Acta. 2014, 413, 68.

[7]. X. F. Wu, H. Neumann, Adv. Synth. Catal. 2012, 354, 3141.

[8]. (a) P. Knochel, P. Jones, Organozinc reagents: A practical approach, Oxford University Press, Oxford, 1999; (b) W. A. Herrmann, Synthetic Methods of Organometallic and Inorganic Chemistry: Catalysis, Georg Thieme Verlag, Stuttgart, 2002.

[9]. (a) E. Negishi, A. O. King, N. Okukado, J. Org. Chem. 1977, 42, 1821; (b) S. Reformatsky, J. Russ. Phys. Chem. Soc. 1890, 22, 44; (c) H. E. Simmons, R. D. Smith, J. Am. Chem. Soc. 1958, 80, 5323; (d) E. Negishi, T. Takahashi, A. O. King, Org. Synth. 1993, 8, 430.

[10]. S. Das, D. Addis, K. Junge, M. Beller, Chem. Eur. J. 2011, 17, 12186.

[11]. K. Junge, K. Moeller, B. Wendt, S. Das, D. Goerdes, K. Thurow, M. Beller, Chem. Asian J. 2012, 7, 314.

[12]. S. Pang, J. Peng, J. Li, Y. Bai, W. Xiao, G. Lai, Chirality 2013, 25, 275.

[13]. O. O. Kovalenko, H. Adolfsson, Chem. Eur. J. 2015, 21, 2785.

[14]. M. Szewczyk, A. Bezłada, J. Mlynarski, ChemCatChem 2016, 8, 3575.

[15]. J. L. Lortie, T. Dudding, B. M. Gabidullin, G. I. Nikonov, ACS Catal. 2017 $7,8454$.

[16]. (a) A. J. Lennox, G. C. Lloyd-Jones, Chem. Soc. Rev. 2014, 43, 412; (b) A. Suzuki, J. Organomet. Chem. 1999, 576, 147; (c) N. Miyaura, A. Suzuki, Chem. Rev. 1995, 95, 2457; d) D. S. Matteson, Chem. Rev. 1989, 89, 1535; (e) S. Rej, A. Das, T. K. Panda, Adv. Synth. Catal. 2021, doi 10.1002/adsc.202100950.

[17]. S. Mandal, S. Mandal, K. Geetharani, Chem. Asian J. 2019, 14, 4553.

[18]. X. Wang, Y. Zhang, D. Yuan, Y. Yao, Org. Lett. 2020, 22, 5695.

[19]. R. K. Sahoo, M. Mahato, A. Jana, S. Nembenna, J. Org. Chem. 2020, 85, 11200.

[20]. R. K. Sahoo, N. Sarkar, S. Nembenna, Angew. Chem. Int. Ed. 2021, 60, 11991.

[21]. Z. Chen, X. D. Nie, J. T. Sun, A. M. Yang, B. G. Wei, Org. Biomol. Chem. 2021, 19, 2492.

[22]. (a) B. S. Huchenski, A. W. Speed, Org. Biomol. Chem. 2019, 17, 1999; (b) A. D. Bage, T. A. Hunt, S. P. Thomas, Org. Lett. 2020, 22, 4107; (c) A D. Bage, K. Nicholson, T. A. Hunt, T. Langer, S. P. Thomas, ACS Catal. 2020, 10, 13479; (d) D. Vidović, Reference Module in Chemistry,
Molecular Sciences and Chemical Engineering, Elsevier, 2021, ISBN 9780124095472, https://doi.org/10.1016/B978-0-12-820206-7.00052-4.

[23]. (a) J. Bhattacharjee, M. Sachdeva, I. Banerjee, T. K. Panda, J. Chem Sci. 2016, 128, 875; (b) A. Harinath, K. Bano, S. Ahmed, T. K. Panda, Phosphorus, Sulfur, and Silicon and the Related Elements 2018, 193, 23; (c) S. Das, J. Bhattacharjee, T. K. Panda, New J. Chem. 2019 43, 16812; (d) G. S. Kumar, A. Harinath, R. Narvariya, T. K. Panda, Eur. J. Inorg. Chem. 2020, 2020, 467; (e) S. Das, R. Kumar, A. Devadkar, T. K. Panda, Asian J. Org. Chem. 2020, 9, 1217.

[24]. J. J. Li, L. Guo, Z. Tian, M. Tian, S. Zhang, K. Xu, Y. Qian, Zhe Liu, Dalton Trans., 2017, 46, 15520.

[25]. O. I. Afanasyev, E. Kuchuk, D. L. Usanov, D. Chusov, Chem. Rev. 2019, 119, 11857.

[26]. (a) J. S. Parker, S. A. Bowden, C. R. Firkin, J. D. Moseley, P. M. Murray, M. J. Welham, R. Wisedale, M. J. Young, W. O. Moss, Org. Process Res Dev. 2003, 7, 67. (b) J. D. Moseley, W. O. Moss, M. J. Welham, Org Process Res. Dev. 2001, 5, 491. (c) M. D. Bomann, I. C. Guch, M. DiMare J. Org. Chem. 1995, 60, 5995

[27]. (a) S. Sato, T. Sakamoto, E. Miyazawa, Y. Kikugawa, Tetrahedron, 2004 60, 7899. (b) S. Uchiyama, Y. Inaba, M. Matsumoto, G. Suzuki, Anal. Chem. 2009, 81, 485

[28]. A. Heydari, H. Tavakol, S. Aslanzadeh, J. Azarnia, N. Ahmadi, Synthesis 2005, 2005, 627.

[29]. H. C. Brown, J. V. B. Kanth, P. V. Dalvi, M. Zaidlewicz, J. Org. Chem. 1999, 64, 6263

[30]. E. R. Burkhardt, B. M. Coleridge, Tetrahedron Lett. 2008, 49, 5152.

[31]. M. A. Peterson, A. Bowman, S. Morgan, Synth. Commun. 2002, 32, 443.

[32]. F. Neese, Comput. Mol. Sci., 2012, 2, 73.

[33]. J. P. Perdew, Phys. Rev. B., 1986, 33, 8822.

[34]. A. D. Becke, Phys. Rev. A, 1988, 38, 3098

[35]. S. Grimme, S. Ehrlich and L. Goerigk, J. Comput. Chem., 2011, 32, 1456

[36]. F. Weigend and R. Ahlrichs, Phys. Chem. Chem. Phys., 2005, 7, 3297. 